\title{
Evaluation of Therapeutic Efficacy of Adjustable Mandibular Advancement Device in the Management of Obstructive Sleep Apnea
}

\author{
${ }^{1}$ Amit Bansal, ${ }^{2}$ B Jayan, ${ }^{3}$ Prasanna Kumar MP, ${ }^{4}$ Mohit Sharma, ${ }^{5}$ Sunil Kumar
}

\begin{abstract}
Introduction: Medical dental sleep appliance (MDSA) is an adjustable mandibular advancement device (MAD) recommended for treatment of snoring and obstructive sleep apnea (OSA). There are very few studies on Indian population which evaluate the therapeutic efficacy of mandibular advancement devices in the management of OSA.
\end{abstract}

Materials and Methods: A prospective clinical study was carried out. Twenty polysomnography diagnosed OSA patients fulfilling the inclusion and exclusion criteria were treated with MDSA and changes in pre and post-treatment sleep para-meters (apneahypopnea index (AHI) and epworth sleepliness scale (ESS)) were recorded.

Results: Mean differences in pre- $\left(T_{1}=30.7 \pm 5.0\right)$ and posttreatment $\left(\mathrm{T}_{2}=17.2 \pm 3.9\right) \mathrm{AHI}$ values and ESS pre-treatment $\left(T_{1}=17.2 \pm 0.6\right)$ and post-treatment $\left(T_{2}=10.9 \pm 0.9\right)$ were highly statistically significant $(p<0.001)$. Clinically the maximum improvement was observed in mild and moderate OSA cases. Although significant clinical improvement was also observed in severe OSA cases, the post-treatment AHI and ESS were still high.

Conclusion: MDSA is a non-invasive, low risk and cost-effective treatment option for patients suffering from mild and moderate obstructive sleep apnea and also in cases of severe OSA who are not comfortable with CPAP or not willing for surgery.

Keywords : AHI, ESS, MDSA, OSA

How to cite this article: Bansal A, Jayan B, Kumar PMP, Sharma M, Kumar S. Evaluation of Therapeutic Efficacy of Adjustable Mandibular Advancement Device in the Management of Obstructive Sleep Apnea. Indian Sleep Med 2018;13(1):5-12.

Source of support: Nil

Conflict of interest: None

\section{INTRODUCTION}

Obstructive Sleep Apnea (OSA) is a condition that results

${ }^{1,5}$ Graded Specialist Orthodontics, ${ }^{2}$ Commandant, ${ }^{3}$ Professor and HOD, ${ }^{4}$ Reader

1,3,4,5Armed Forces Medical College, Pune, Maharashtra, India

${ }^{2}$ Air Force Institute of Dental Sciences, Pune, Maharashtra, India

Corresponding Author: Amit Bansal, Graded Specialist Orthodontics, Armed Forces Medical College, Pune, Maharashtra, India, Tel : 8390551912, e-mail: dr.bansal1912@ gmail.com due to partial or complete obstruction of airway when patient assumes a supine position and goes to sleep. In the last three decades, mandibular advancement devices (MAD) have been used to treat OSA. MADs move the mandible forward to improve upper airway patency and are the most evaluated type of appliances. An influential review of oral appliance (OA) therapy for OSA, accompanied by practice parameters of American Sleep Disorder Association signaled the entry of dentistry into mainstream sleep medicine. ${ }^{1}$ Adjustable mandibular advancement appliance became predominant form of dental therapy for sleep-disordered breathing since the 1990s. ${ }^{2}$ Controlled studies in the last decade and a half have shown effectiveness and preference for oral appliances compared to Continuous Positive Air Pressure (CPAP) in mild and moderate cases. ${ }^{3-5}$ Studies have also reported gross improvement in severe cases if patient selection is based on stringent inclusion criteria. ${ }^{6}$

MADs have shown to significantly improve objective parameters, such as AHI, arousal index, snoring and arterial oxygenation. They have shown to improve quality of life, blood pressure and improvements in cardiovascular outcomes and inflammatory markers similar to CPAP. ${ }^{7}$

There are several designs of adjustable mandibular advancement devices for OSA patients but there is no consensus on the design of adjustable MAD. Medical Dental Sleep Appliance is an adjustable MAD and a third generation intraoral dental device recommended for treatment of snoring and OSA. It is readily available in India and one of the most cost-effective appliances, custom fabricated in the dental laboratory.

There are very few studies on Indian population which evaluate the therapeutic efficacy of mandibular advancement devices in the management of OSA. ${ }^{6-8}$ In view of the above, it was proposed to evaluate the therapeutic efficacy of medical dental sleep appliance, an adjustable MAD in the management of OSA objectively and subjectively. To evaluate the therapeutic efficacy of MDSA, an adjustable MAD, in the management of OSA by testing the null hypothesis that there is no difference in pre- and post-treatment sleep parameters in patients treated with MDSA.

The objectives of the study were:- 
- To compare baseline and post-treatment apneahypopnea index (AHI) scores.

- To compare baseline and post-treatment epworth sleepiness scale (ESS).

\section{MATERIALS AND METHODS}

A prospective clinical study was carried out at the Department of Orthodontics and Dentofacial Orthopedics of Armed Forces Medical College, Pune. Twenty polysomnography diagnosed obstructive sleep apnea patients referred from Dept of Pulmonary and Sleep Medicine, Military Hospital (CTC), Pune and Dept of Otorhinolaryngology, Armed Forces Medical College, Pune, fulfilling the inclusion and exclusion criteria were inducted for the study.

\section{Inclusion Criteria}

- PSG diagnosed adult OSA cases (mild, moderate OSA cases and severe OSA cases not amenable to CPAP therapy or surgery).

- $\quad \mathrm{BMI}<30 \mathrm{~kg} / \mathrm{m}^{2}$

- Any of the following two findings on the lateral cephalogram

- $\mathrm{SNB}<78^{\circ}$

- $\mathrm{MPH}$ (Hyoid distance) $>15 \mathrm{~mm}$

- Angle ANB $>4^{\circ}$

- Posterior airway space (linear distance from the posterior border of the tongue to pharyngeal wall measured along the B-Go line $)<10 \mathrm{~mm}$

- Minimum mandibular protrusion of $5 \mathrm{~mm}$

- Minimum interincisal opening of $35 \mathrm{~mm}$

\section{Exclusion Criteria}

- Central sleep apnea

- Mixed sleep apnea

- Severe accompanying respiratory disorders

- Advanced periodontal disease

- Partial edentulous cases $(<14$ healthy permanent teeth)

- Adenotonsillar hypertrophy, septal deviation, turbinate hypertrophy or nasal polyp

\section{Sample Size Calculation}

The sample size was calculated for one-tailed hypothesis testing for the hypothesis $\mathrm{H}_{0}: \mu_{1}-\mu_{2}=0$ against $\mathrm{H}_{1}: \mu_{1}-\mu_{2}$ $<0$ with $\alpha=0.05(5 \%)$ and $\beta=0.80(80 \%)$. Pre and Post AHI and ESS scores (based on data from reference no. 6) were as follows:

\begin{tabular}{l|l|c|c|c|c}
\hline \multirow{2}{*}{ S. No } & \multirow{2}{*}{ Parameter } & \multicolumn{2}{|c|}{ Pre } & \multicolumn{2}{c}{ Post } \\
\cline { 3 - 6 } & & Mean & $S D$ & Mean & $S D$ \\
\hline 1. & AHI & 47.63 & 7.93 & 20.61 & 5.78 \\
2 & ESS & 12.70 & 1.82 & 8.50 & 1.26 \\
\hline
\end{tabular}

Thus, minimum sample size required works out to be 4 for data for AHI and 7 for data for ESS. In this study, 20 subjects were included.

\section{Procedure Methodology}

All the study subjects were subjected to lateral cephalometric roentenography as per standard protocol. Lateral cephalograms were recorded at end expiration and the patients were asked not to deglute/swallow during the process of radiography. All the radiographs were traced by a single operator and five lateral cephalograms were retraced after one week by the same operator to rule out any discrepancies.

Data collection was divided into two sections as follows:

Sleep-disordered breathing form was used to record the medical and sleep history including an ESS. Using this scale, the subjects were asked to rate, on a scale of 0-3, how likely they were to doze off or fall asleep in each of the eight different situations. In the ESS, a 4-point scoring scale was used as under:

- 0 = would never doze

- 1 = slight chance of dozing

- 2 = moderate chance of dozing

- 3 = high chance of dozing

The ESS was recorded pretreatment and again posttreatment after assessment of subjective improvement.

Baseline and post-treatment polysomnography (PSG) was utilized for AHI.

Patients meeting the selection criteria were taken up for treatment with the Medical Dental Sleep Appliance (MDSA Pty Ltd, Australia) (Figs 1 and 2), an adjustable mandibular advancement device. Titration was done with a key provided in the kit depending on subjective improvement. Titration did not exceed $70 \%$ of maximum protrusion. The patients were recalled weekly to ascertain subjective improvement in sleep parameters. After ascertaining subjective response from the patient or bed partner in terms of reduction/cessation of snoring, excessive day time sleepiness and regularity in use of the prescribed appliance, the patient was subjected to recording of ESS and PSG with MDSA in situ. The patient was observed for discomfort in the TMJ area or teeth, excessive salivation or any other appliance related problems. 


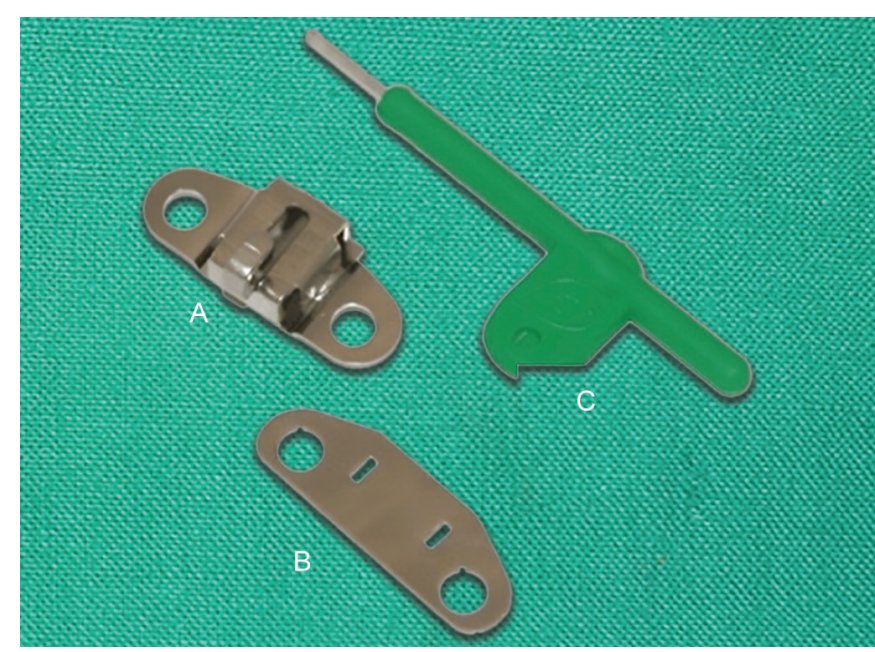

Fig. 1: Components of medical dental Sleep appliance (MDSA) (A) Titratable screw (B) Lower platform (C) Allen key

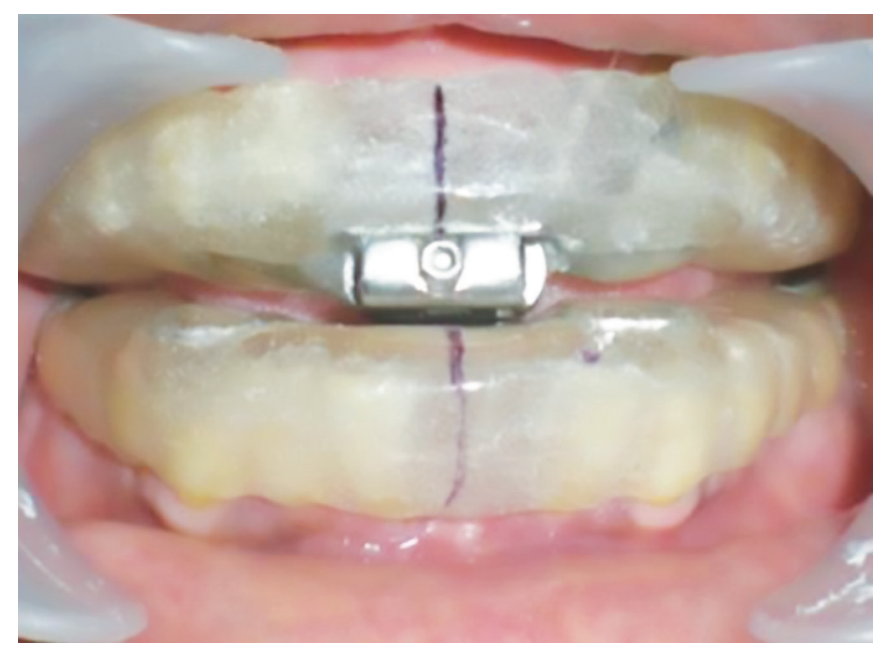

Fig. 2: MDSA delivered to patient

\section{Data Compilation and Statistical Analysis}

The entire data were statistically analyzed using statistical package for social sciences (SPSS ver 11.5, Inc. Chicago, USA) for MS Windows.

The data on pre- and post-treatment AHI and ESS is presented as Mean (+ Standard Deviation). The statistical significance of difference of pre- and post-treatment parameters was tested using paired ' $t$ ' test, after confirming the underlying normality assumption using ShapiroWilk's test. The statistics on the difference is presented as mean value along with the $95 \%$ confidence interval.

The $p$-values less than 0.05 were considered to be statistically significant. All the hypotheses were formulated using two tailed alternatives against each null hypothesis (hypothesis of no difference).

\section{RESULTS}

\section{Descriptive Statistics for Patient Variables}

Data compiled from the study is consolidated as Table 1.
The mean + SD for pretreatment AHI for the group was calculated to be $30.7+5.0$ as shown in Table 2 . Seven cases $(35.0 \%)$ had mild OSA ( $\mathrm{AHI}=5-15$ events $/ \mathrm{hr})$, five cases $(25.0 \%)$ had moderate OSA ( $\mathrm{AHI}=15-30$ events $/ \mathrm{hr})$ and eight cases $(40 \%)$ had severe OSA (AHI $>30$ events $/ \mathrm{hr}$ ).

Out of the 20 cases studied, 6 cases $(30.0 \%$ ) had a BMI between 18.5 to 24.9 (Healthy category) and 14 cases (70.0\%) had a BMI between 25.0 to 29.9 (Overweight category). The mean $\pm \mathrm{SD}$ of BMI of the entire group of cases was $26.5 \pm 2.2 \mathrm{~kg} / \mathrm{m}^{2}$.

\section{Descriptive Statistics for Pre- and Post-treatment Variables}

To identify the significance of post-operative changes with respect to pre-operative values, a Student's paired t-test was used for all pre and post AHI and pre and post ESS after confirming the underlying normality assumption using the Shapiro-Wilk's test.

Results of comparison for AHI pre- $\left(\mathrm{T}_{1}=30.7 \pm 5.0\right)$ and post-treatment $\left(T_{2}=17.2 \pm 3.9\right)$ values show an average change in $T_{2}$ values of 13.5 which is highly statistically significant $(\mathrm{p}<0.001)$.

Comparison for ESS pre- $\left(\mathrm{T}_{1}=17.2 \pm 0.6\right)$ and posttreatment $\left(T_{2}=10.9 \pm 0.9\right)$ values shows there is an average decrease of 6.3. This mean difference is highly statistically significant $(\mathrm{p}<0.001)$ and shows the improvement in nighttime sleep quality and reduction in daytime sleepiness with MDSA.

For mild OSA cases, comparison for AHI pre- $\left(\mathrm{T}_{1}=\right.$ $10.8 \pm 2.6)$ and post-treatment $\left(T_{2}=4.5 \pm 3.9\right)$ values show an average change in $\mathrm{T}_{2}$ values of 6.4 which is statistically significant $(\mathrm{p}<0.005)$ and ESS pre- $\left(\mathrm{T}_{1}=15.0 \pm 2.24\right)$ and post-treatment $\left(T_{2}=8.57 \pm 3.6\right)$ values shows there is average decrease of 6.43 . This mean difference is extremely statistically significant $(\mathrm{p}<0.001)$.

For moderate OSA cases, AHI pre-treatment $\left(\mathrm{T}_{1}=21.8\right.$ $\pm 4.1)$ and post-treatment $\left(T_{2}=10.3 \pm 2.1\right)$ values show an average change in $T_{2}$ values of 11.5 which is extremely statistically significant $(\mathrm{p}<0.001)$ and ESS pre- $\left(\mathrm{T}_{1}=17.0 \pm\right.$ 1.2) and post-treatment $\left(T_{2}=10.8 \pm 1.3\right)$ values shows there is an average decrease of 6.2 which was again extremely statistically significant $(\mathrm{p}<0.001)$.

AHI pre- $\left(\mathrm{T}_{1}=53.5 \pm 17.2\right)$ and post-treatment $\left(\mathrm{T}_{2}=\right.$ $32.6 \pm 18.8)$ values for severe OSA cases show an average change at $\mathrm{T}_{2}$ of 20.9 which is statistically significant $(\mathrm{p}<$ $0.005)$ and ESS pre- $\left(\mathrm{T}_{1}=19.1 \pm 2.8\right)$ and post-treatment $\left(\mathrm{T}_{2}=13.0 \pm 4.1\right)$ values shows there is an average decrease of 6.1 which was again statistically highly significant $(\mathrm{p}$ $=0.001$ ).

Clinically, it was observed that maximum improvement in snoring and daytime sleepiness was observed in mild and moderate OSA cases. Although significant 
Table 1: Consolidated data

\begin{tabular}{|c|c|c|c|c|c|c|c|c|c|c|c|}
\hline S.No & Age & Gender & $B M I$ & $S N B$ & $A N B$ & $M P H$ & PAS & Pre AHI & Post AHI & Pre ESS & Post ESS \\
\hline 1. & 42 & $M$ & 25.2 & 77 & 5 & 20 & 9 & 17.3 & 7.4 & 16 & 10 \\
\hline 2. & 60 & $M$ & 26.6 & 80 & 2 & 18 & 7 & 20.9 & 10.9 & 19 & 12 \\
\hline 3. & 63 & $M$ & 29.3 & 81 & 4 & 21 & 6 & 56.7 & 40.0 & 21 & 17 \\
\hline 4. & 44 & $M$ & 24.4 & 76 & 7 & 15 & 9 & 40.6 & 37.4 & 18 & 16 \\
\hline 5. & 50 & $F$ & 25.4 & 77 & 6 & 14 & 10 & 8.8 & 2.5 & 13 & 8 \\
\hline 6. & 40 & M & 22.7 & 78 & 6 & 17 & 8 & 35.4 & 2.9 & 16 & 7 \\
\hline 7. & 68 & $M$ & 24.7 & 77 & 4 & 19 & 7 & 63.4 & 28.8 & 22 & 14 \\
\hline 8. & 40 & $M$ & 27.8 & 77 & 7 & 13 & 11 & 27.8 & 10.2 & 16 & 11 \\
\hline 9. & 49 & $M$ & 29.0 & 80 & 9 & 19 & 12 & 60.7 & 50.4 & 18 & 15 \\
\hline 10. & 57 & $M$ & 29.5 & 76 & 8 & 16 & 10 & 12.3 & 1.2 & 13 & 6 \\
\hline 11. & 43 & $M$ & 29.4 & 79 & 6 & 15 & 9 & 8.3 & 2.1 & 14 & 5 \\
\hline 12. & 55 & $M$ & 27.8 & 78 & 4 & 30 & 7 & 87.5 & 61.5 & 23 & 17 \\
\hline 13. & 65 & $M$ & 28.6 & 76 & 6 & 21 & 8 & 39.9 & 23.3 & 15 & 10 \\
\hline 14. & 52 & $\mathrm{~F}$ & 24.2 & 78 & 4 & 12 & 12 & 24.0 & 13.2 & 17 & 12 \\
\hline 15. & 35 & $M$ & 22.5 & 79 & 2 & 17 & 8 & 7.8 & 3.2 & 15 & 9 \\
\hline 16. & 50 & $M$ & 28.0 & 74 & 8 & 17 & 10 & 12.9 & 2.8 & 17 & 6 \\
\hline 17. & 59 & $M$ & 27.3 & 76 & 5 & 15 & 9 & 14.8 & 12.4 & 19 & 16 \\
\hline 18. & 49 & $M$ & 25.4 & 77 & 6 & 14 & 11 & 19.3 & 10.0 & 17 & 9 \\
\hline 19. & 51 & $M$ & 27.2 & 79 & 4 & 16 & 9 & 11.1 & 7.2 & 14 & 10 \\
\hline 20. & 63 & $M$ & 24.3 & 74 & 10 & 12 & 6 & 44.1 & 16.3 & 20 & 8 \\
\hline
\end{tabular}

clinical improvement was also observed in severe OSA cases, the post-treatment AHI and ESS were still high.

Comparison of pre- and post-treatment AHI and ESS for the mean of differences for mild, moderate and severe OSA are presented in Graphs 1A to 1C.

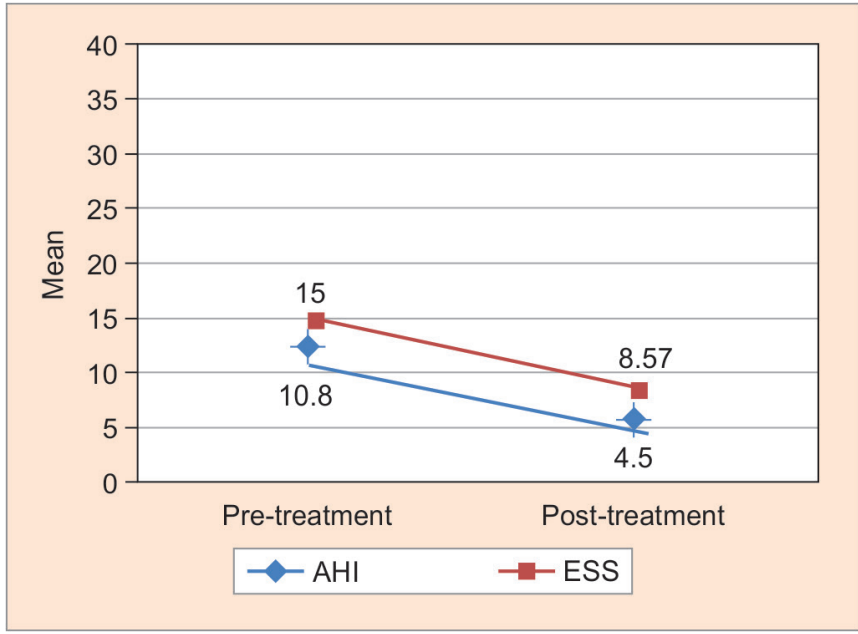

Graph 1A: Comparison of pre- and post-treatment AHI and ESS (Mild OSA)

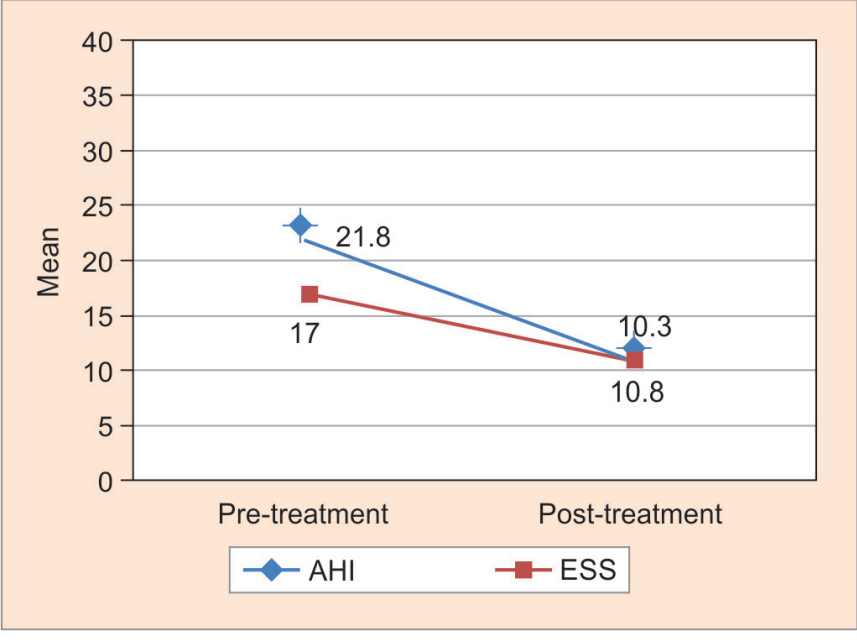

Graph 1B: Comparison of pre- and post-treatment AHI and ESS (Moderate OSA)

\section{Adverse Effects of MDSA}

Nine participants experienced increased salivation and difficulty in sleeping with the appliance in situ. However, these effects decreased gradually and most patients comfortably wore the appliance for the entire duration of sleep after 1 week of appliance delivery. 


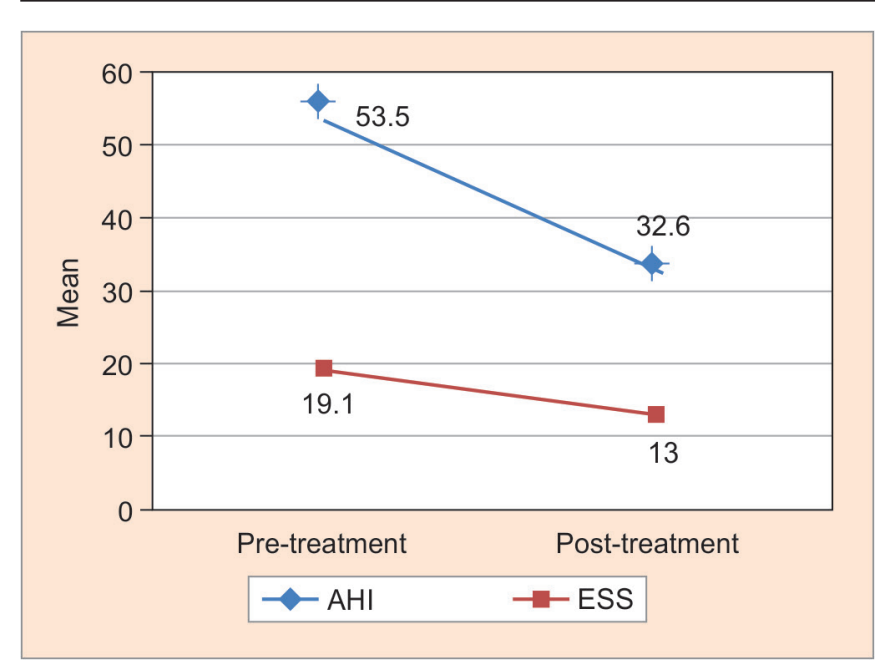

Graph 1C: Comparison of pre- and post-treatment AHI and ESS (Severe OSA)

However, one participant (S.No 4) experienced continued discomfort with the appliance during sleep and also complained of appliance dislodgement during sleep. Despite best efforts to assure the participant and performing suitable remedial actions, the problems persisted and he showed minimum decrease in $\mathrm{AHI}(\mathrm{T} 1=40.6$ and $\mathrm{T} 2=$ 37.4) and ESS (T1 = 18 and T2 = 16).

None of the other patients showed any adverse effects in the dentition or masticatory system due to wearing of MDSA.

\section{DISCUSSION}

Obstructive sleep apnea is a common sleep disorder characterized by recurring collapse of the upper airway during sleep, resulting in sleep fragmentation and oxygen desaturation. OSA is defined as the occurrence of five or more episodes of complete (apnea) or partial (hypopnea) upper airway obstruction per hour of sleep (apnea-hypopnea index). ${ }^{9}$ Daytime symptoms such as sleepiness, cognitive impairment, and effects on quality of life require appropriate treatment. Furthermore, the association of OSA with increased risk of motor vehicle accidents, cardiovascular morbidity and the subsequent increased risk of mortality, emphasize the need for effective long-term treatment. ${ }^{10}$

Most common treatment options for OSA include behavioral strategies, such as weight reduction, alcohol avoidance, smoking cessation, and alteration of sleeping position, a range of surgical procedures of the upper airway, continuous positive airway pressure (CPAP) and oral appliances. ${ }^{11}$ The gold standard treatment for OSA is to pneumatically splint open the upper airway during sleep using continuous positive airway pressure. CPAP is highly efficacious in preventing upper airway collapse but patient acceptance, tolerance, and adherence are often low, thereby reducing effectiveness. ${ }^{3}$
Hence, there is a major need for effective alternative treatment modalities. Custom made mandibular advancement devices are an effective treatment option for snoring, upper airway resistance syndrome and obstructive sleep apnea. Evidence-based data indicates their efficacy, and international sleep societies recommend oral appliance therapy for patients with sleep-related breathing disorders. ${ }^{1,10,12}$ The rationale behind the efficacy of MADs is that advancement of the mandible and tongue improves upper airway patency during sleep by enlarging the upper airway and by decreasing upper airway collapsibility, thereby preventing collapse during sleep. ${ }^{4}$ A mandibular advancement appliance should positively place the lower jaw in a predictable and maximally therapeutic position.

MDSA is a third generation two-piece appliance with separate components on maxilla and mandible. A separate component for each jaw makes fitting easier and makes it more difficult to dislodge because the removal of the appliance is in different path of opening. ${ }^{13}$ Connecting the upper and lower appliance is accomplished by a single hook and latch in the anterior region. Because of the versatility and ease of adaptation, the MDSA is more effective than the one piece appliance. The appliance design restricts all backward movements while still allowing the patient to move the mandible forward and side to side and open the mouth if necessary.

There are numerous studies highlighting the benefits of different mandibular advancement devices in OSA. ${ }^{3,5-}$ 7,14-33 However, a review on oral appliances therapy for OSA has pointed out that most studies exclude the patients with severe OSA, thus there exists a significant source of bias ${ }^{11}$. Furthermore, only a few studies have studied the third generation adjustable MADs ${ }^{6,7,17,23-25,31}$ and only one study evaluated the efficacy of the medicaldental sleep appliance for the management of OSA. ${ }^{25}$

There is also a paucity of studies with regard to prescribing oral appliances with definite inclusion and exclusion criteria. Some studies have shown that if cephalometric findings like reduced posterior airway space/retroglossal space, increased hyoid-mandibular plane distance, retrognathic mandible and $\mathrm{BMI}<30 \mathrm{Kg} /$ $\mathrm{m}^{2}$ are considered, along with established dental norms for oral appliance therapy, $70 \%$ mandibular protrusion with MDSA can bring about desired therapeutic efficacy in severe OSA cases. ${ }^{6,7}$

Keeping these criteria in mind, this prospective clinical study was performed to assess the therapeutic efficacy of MDSA in the treatment of OSA.

\section{Sample Characteristics}

The study sample consisted of 20 subjects with 18 
males $(90 \%)$ and 2 females (10\%). This gender bias was expected as female hormones have been shown to have a protective action against OSA in a review article by Banno and Kryger. ${ }^{34}$ They reported that progesterone, a female hormone, has respiratory stimulant properties while testosterone, a male hormone, has been reported to increase upper airway collapsibility, which may increase the risk for the development of OSAS. They also stated that due to the hormonal changes, the prevalence of OSAS in postmenopausal females is higher than in premenopausal females. This correlation was re-established in our study as both the female subjects reported to be post-menopausal.

The mean BMI of the study sample was $26.5 \pm 2.2 \mathrm{~kg} /$ $\mathrm{m}^{2}$. Only patients with $\mathrm{BMI}<30 \mathrm{~kg} / \mathrm{m}^{2}$ were included in the study to rule out any confounding factor that may arise due to a positive correlation between increased BMI and severity of OSA as shown in various studies. ${ }^{35-38}$. These studies suggest that the shape and dimension of the pharyngeal lumen was more dependent on BMI than on the presence of OSA and a higher BMI was related to a more severe OSA.

The mean $+\mathrm{SD}$ of baseline AHI for the group was $30.7+5.0$.

Seven cases (35.0\%) had mild OSA, five cases $(25.0 \%)$ had moderate OSA and eight cases $(40 \%)$ had severe OSA who did not agree for surgery or were uncomfortable with CPAP. This was in agreement with scientific appraisals and international guidelines of different sleep societies which recommend oral appliance treatment for primary snoring, upper airway resistance syndrome, mild to moderate OSA (AHI up to $30 / \mathrm{h}$ ) and in severe cases, not amenable to CPAP therapy. ${ }^{1,12}$

\section{Therapeutic Effects of MDSA}

Due to strict adherence to the inclusion and exclusion criteria, we observed a highly significant improvement in AHI scores. The mean AHI scores decreased from 30.7 \pm 5.0 to $17.2 \pm 3.9$. As per international norms, $5050 \%$ reduction in AHI scores is considered successful treatment ${ }^{12}$. We could not achieve the same in ten cases. This can be attributed to the fact that 8 cases $(40 \%)$ of the study population treated had severe OSA (AHI > 30), where oral appliance therapy is not the first choice. However, the overall improvement in AHI scores in the study sample was highly statistically significant $(\mathrm{p}<0.001)$. Ten cases in the present study showed more than $50 \%$ reduction in AHI scores.

In the present study, post-treatment AHI scores did not show significant difference in two cases (S.No 4 and 17 of Table 1). It is not clear as to why oral appliance were effective in most except two cases. Various individual ana- tomic factors, the degree of vertical and sagittal opening, the skeletal pattern of the skull and oropharyngeal tissue compliance may influence therapeutic efficacy, as reported in the literature. ${ }^{10}$ Patient compliance is another factor to be taken into consideration as the initial difficulties are experienced with appliance wear and sleep parameters may take some time to improve. Although constant motivation and counseling was carried out, some subjects tended to be impatient with the delay in response.

Clinically, most patients showed subjective improvement in the form of reduction in snoring, as reported by bed partner and decreased daytime sleepiness as assessed by the Epworth sleepiness scale.

ESS scores reduced from $17.2 \pm 0.6$ to $10.9 \pm 0.9$ which was highly statistically significant $(\mathrm{p}<0.001)$. Clinically these changes manifested as improved nighttime sleep quality with reduction in snoring and decreased daytime sleepiness. Decrease in snoring was reported almost immediately in all cases however the daytime sleepiness showed improvement over a period of 4-6 months. The time taken can be due to the 'sleep debt' caused due to the decreased nighttime sleep quality in OSA patients. However, in the two cases in which the AHI did not improve, there was no significant clinical improvement highlighting the proven correlation between $\mathrm{AHI}$ and ESS.

When these changes are correlated clinically it was observed that maximum improvement in snoring and day time sleepiness was observed in mild and moderate OSA cases. In severe OSA cases, although the significant clinical improvement was observed, the post-treatment $\mathrm{AHI}$ and ESS were still high in most cases. These findings are in agreement with a randomized controlled trial by Barnes et $\mathrm{a}^{25}$ who reported MDSA to be effective in the management of mild and moderate OSA. A prospective study by Marklund et al. ${ }^{27}$ also demonstrated a significant reduction in AHI in patients with MADs in a wide range of OSA severities but the greatest improvement was observed in patients with mild and moderate cases. Similarly, a randomized clinical trial by Johnston et al. ${ }^{39}$ concluded that mandibular advancement appliance was less effective in subjects with most severe OSA (pretreatment $\mathrm{AHI}>50$ ). In a recent meta-analysis, Sharples and co-workers ${ }^{40}$ have shown that MAD results in a significant improvement in post-treatment $\mathrm{AHI}$, and that the estimate of effect was similar irrespective of baseline $\mathrm{AHI}$ and the effect of MAD on subjective day time sleepiness measured using the ESS followed a similar pattern.

\section{Adverse Effects of MDSA}

All the participants were followed up for a minimum period of 6 months post appliance delivery to ascertain 
any short-term side effects. Immediately after appliance delivery, nine participants experienced increased salivation and difficulty in sleeping with the appliance. However these effects decreased gradually in all but one patient, and they comfortably wore the appliance for the entire duration of sleep after one week of appliance delivery. Similar findings were reported by various studies in which over $80 \%$ of the patients reported some sort of adverse effect, mostly excessive salivation or dry mouth, that they attributed to the device. ${ }^{28,41,42}$

None of the patients showed any adverse effects in the dentition, in the form of changes in occlusion, or masticatory system in the form of pain and discomfort in TMJ due to wearing the MDSA over a 6 month period. Bondemark et al. ${ }^{43}$ compared masticatory system symptoms such as temporomandibular pain or clicking, headache, jaw muscle fatigue or soreness to baseline data or to a control group without mandibular repositioning appliances and reported no increase in the incidence of such symptoms. One long-term study by Almeida et al. ${ }^{44}$ showed a more marked change in overjet and overbite. However, another prospective long-term study by Marklund et al. ${ }^{45}$ did not show any further changes in occlusion. Literature suggests that these changes seemed to develop during the first few years of use of the device and then stabilize. None of the studies with a follow-up period of less than 6 months reported clinical signs of changes in occlusion. ${ }^{41,42}$

\section{CONCLUSION}

This prospective clinical study was conducted to evaluate the therapeutic efficacy of Medical Dental Sleep Appliance (MDSA), an adjustable mandibular advancement device, in the management of OSA by testing the null hypothesis that there is no difference in pre and post treatment sleep parameters in patients treated with MDSA. The following conclusions can be drawn from the study:

The null hypothesis is rejected as there is a highly significant difference in pre- and post-treatment sleep parameters, i.e., $\mathrm{AHI}$ and ESS scores, in patients treated with MDSA.

Treatment with MDSA can benefit OSA cases with improvement in nighttime sleep quality and daytime sleepiness, as assessed by reduction in AHI and ESS scores.

MDSA is a non-invasive, low risk and cost-effective treatment option for patients suffering from mild and moderate obstructive sleep apnea and also in cases of severe OSA who are not comfortable with CPAP or not willing for surgery provided that co-morbidities are carefully analyzed and patient compliance is adequate to achieve optimal results.

\section{REFERENCES}

1. American Sleep Disorders Association Standard of Practice committee: Practice parameters for the treatment of snoring and obstructive sleep apnea with oral appliances. Sleep. 1995; 18(6): 511-513.

2. Lowe AA. Dental appliances for snoring and Obstructive sleep apnea. In: Kryger M, Roth T, Dement W, editors. Principles and practice of sleep medicine. $3^{\text {rd }}$ edition. Philadelphia: WB Saunders 2000; 929-939.

3. Ferguson KA, Ono T, Lowe AA, Keenan SP, Fleetham JA. A randomized crossover study of an oral appliance vs nasal-continuous positive airway pressure in the treatment of mild-moderate obstructive sleep apnea. Chest. 1996; 109:1269-1275.

4. Clark GT, Blumenfeld I, Yoffe N, Peled E, Lavie P. A crossover study comparing the efficacy of continuous positive airway pressure with anterior mandibular positioning devices on patients with obstructive sleep apnea. Chest. 1996; 109:1477-1488.

5. Ferguson KA, Ono T, Lowe AA, Majed SA, Keenan SP, Love LL, et al. A short-term controlled trial of an adjustable oral appliance for the treatment of mild to moderate obstructive sleep apnoea. Thorax. 1997; 52:362-368.

6. Jayan B, Prasad BNBM, Kamat UR, Kharbanda OP, Bhattacharrya D. Therapeutic efficacy of Thornton adjustable positioned in the management of patients with severe Obstructive sleep apnea: A Pilot study. Indian J Sleep Med. 2008; 3.3:97-101.

7. Jayan B, Prasad BNBM, Rajput AK, Bhattacharya R, Dhiman RK. Management of Obstructive Sleep Apnea with Oral Appliances: Our Experience. Indian J Sleep Med. 2006; 1.4:204-207.

8. Jayan B, Prasad BNBM, Dhiman RK. Role of Oral Appliances in the Management of Sleep Disorders. Med J Armed Forces India. 2009; 65:123-127.

9. Sleep-related breathing disorders in adults: recommendations for syndrome definition and measurement techniques in clinical research. The Report of an American Academy of Sleep Medicine Task Force. Sleep. 1999; 22(5):667-689.

10. Lim J, Lasserson TJ, Fleetham J, Wright JJ. Oral appliances for obstructive sleep apnoea. Cochrane Database of Systematic Reviews. 2006, Issue 1. Art. No.: CD004435.

11. Li W, Xiao L, Hu J. The Comparison of CPAP and Oral Appliances in Treatment of Patients with OSA: A Systematic Review and Meta-analysis. Respir Care. 2013; 58(7):1184-1195.

12. American Academy of Sleep Medicine Practice Parameters for the Treatment of Snoring and Obstructive Sleep Apnea with Oral Appliances: An Update, 2005.

13. Johal A. A review on the use of mandibular advancement appliances in sleep disordered breathing. Dent Update. 2008; 35:230-235.

14. Ichioka M, Tojo N, Yoshizawa M, Chida M, Miyazato I, Taniai S, et al. A dental device for the treatment of obstructive sleep apnea: a preliminary study. Otolaryngol Head Neck Surg. 1991; 104:555-558.

15. Pepin JL, Leger P, Veale D. Side effects of nasal continuous positive airway pressure in sleep apnea syndrome. Study of 193 patients in two French sleep centers. Chest. 1995; 107:375- 381.

16. Wilhelmsson B, Tegelberg $\AA$, Walker- Engström ML, 
Ringqvist M, Andersson L, Krekmanov L, et al. A prospective randomized study of a dental appliance compared with uvulopalatopharyngoplasty in the treatment of obstructive sleep apnoea. Acta Otolaryngol. 1999; 119:503-509.

17. Pancer J, Al-Faifi S, Al-Faifi M, Hoffstein V. Evaluation of variable mandibular advancement appliance for treatment of snoring and sleep apnea. Chest. 1999; 116:1511-1518.

18. Barthlen GM, Brown LK, Wiland MR, Sadeh JS, Patwari J, Zimmerman M. Comparison of three oral appliances for treatment of severe obstructive sleep apnea syndrome. Sleep Med. 2000; 1(4):299-305.

19. Gotsopoulos H, Chen C, Qian J, Cistulli PA. Oral appliance therapy improves symptoms in obstructive sleep apnea: a randomized controlled trial. Am J Respir Crit Care Med. 2002; 166:743-748.

20. Johnston CD, Gleadhill IC, Cinnamond MJ, Gabbey J, Burden DJ. Mandibular advancement appliances and obstructive sleep apnoea: a randomized clinical trial. Eur J Orthod. 2002; 24:251-262.

21. Tan YK, L'Estrange PR, Luo YM, Smith C, Grant HR, Simonds AK. Mandibular advancement splints and continuous positive airway pressure in patients with obstructive sleep apnoea: a randomized cross-over trial. Eur J Orthod. 2002; 24:239-249.

22. Engleman HM, McDonald JP, Graham D, Lello GE, Kingshott RN, Coleman EL. Randomized crossover trial of two treatments for sleep apnea/ hypopnea syndrome: continuous positive airway pressure and mandibular repositioning splint. Am J Respir Crit Care Med. 2002; 166:855-859.

23. Randerath WJ, Heise M, Hinz R, Ruehle KH. An individually adjustable oral appliance vs continuous positive airway pressure in mild-to-moderate obstructive sleep apnea syndrome. Chest. 2002; 122:569-575.

24. Rose EC, Germann M, Sorchter S, Jonas IE. Case Control study in the treatment of Obstructive sleep disordered breathing with a mandibular protrusive appliance. J Orofac Orthop. 2004; 65:489-500.

25. Barnes M, McEvoy RD, Banks S, Tarquinio N, Murray CG, Vowles N, et al. Efficacy of positive airway pressure and oral appliance in mild to moderate obstructive sleep apnea. Am J Respir Crit Care Med. 2004; 170:656-664.

26. Gotsopoulos H, Kelly JJ, Cistulli PA. Oral appliance therapy reduces blood pressure in obstructive sleep apnea: a randomized, controlled trial. Sleep. 2004; 27(5):934-941.

27. Marklund M, Stenlund H, Franklin KA. Mandibular advancement devices in 630 men and women with obstructive sleep apnea and snoring: tolerability and predictors of treatment success. Chest. 2004; 125:1270-1278.

28. Izci B, McDonald JP, Coleman EL, Mackay TW, Douglas NJ, Engleman HM. Clinical audit of subjects with snoring \& sleep apnoea/hypopnoea syndrome fitted with mandibular repositioning splint. Respir Med. 2005; 99:337-346.

29. Vecchierini MF, Léger D, Laaban JP, Putterman G, Figueredo M, Levy J, et al. Efficacy and compliance of mandibular repositioning device in obstructive sleep apnea syndrome under a patient-driven protocol of care. Sleep Med. 2008; 9(7):762-769

30. Aarab G, Lobbezoo F, Hamburger HL, Naeije M.Oral Appliance Therapy versus Nasal Continuous Positive Airway Pressure in Obstructive Sleep Apnea: A Random- ized, Placebo-Controlled Trial. Respiration. 2011; 81:411419 .

31. Holley AB, Lettieri CJ, Shah AA. Efficacy of an Adjustable Oral Appliance and Comparison to Continuous Positive Airway Pressure for the Treatment of Obstructive Sleep Apnea Syndrome. Chest. 2011; 140:1511-1516.

32. Vuorjoki-Ranta TR, Lobbezoo F, Tuomilehto H, Könönen M, Pihakari A, Ahlberg J. Mandibular Advancement Device Therapy in Obstructive Sleep Apnea and Snoring in Community Dental Care: Two-year Follow-up Study on Self-reported Sleep Quality, Side Effects, and Compliance. Sleep Disord Ther. 2014; 3:5.

33. Ballanti F, Ranieri S, Baldini A, Cozza P. Long Term Therapeutic Efficacy of a Soft Monobloc Mandibular Advancement Device in Adults with Obstructive Sleep. Scientific World Journal. 2015, Article ID 408469.

34. Banno K, Kryger MH. Sleep apnea: clinical investigations in humans. Sleep Med. 2007; 8:400-426.

35. Tsuchiya M, Lowe AA, Pae EK, Fleetham JA. Obstructive sleep apnoea subtypes by cluster analysis. Am J Orthod Dentofac Orthop. 1992; 101:533-542.

36. Mayer P, Pépin JL, Bettega G, Veale D, Ferretti G, Deschaux $\mathrm{C}$, et al. Relationship between body mass index, age and upper airway measurements in snorers and sleep apnoea patients. Eur Respir J. 1996; 9:1801-1809.

37. Kumar PVG, M Bhatia, M Tripathi, AK Srivastava, S Jain. Obstructive sleep apnoea: a case controlled study. Neurology India. 2003; 51(4):497-499.

38. Lee RW, Chan AS, Grunstein RR, Cistulli PA. Craniofacial phenotyping in obstructive sleep apnoea - A novel quantitative photographic approach. Sleep. 2009; 32(1):3745.

39. Johnston CD, Gleadhill IC, Cinnamond MJ, Peden MW. Oral appliances for management of snoring: a randomized controlled trial. Eur J Orthod. 2001; 23:127-134.

40. Sharples LD, Clutterbuck-James AL, Glover MJ, Bennett MS, Chadwick R, Pittman MA, et al. Meta-analysis of randomised controlled trials of oral mandibular advancement devices and continuous positive airway pressure for obstructive sleep apnoea-hypopnoea. Sleep Medicine Reviews. 2015.

41. Pantin CC, Hillman DR, Tennant M. Dental side effects of an oral device to treat snoring and obstructive sleep apnea. Sleep. 1999; 22(2):237-240.

42. Fritsch KM, Iseli A, Russi EW, Bloch KE. Side effects of mandibular advancement devices for sleep apnea treatment. Am J Respir Crit Care Med. 2001; 164:813-818.

43. Bondemark L, Lindman R. Craniomandibular status and function in patients with habitual snoring and obstructive sleep apnoea after nocturnal treatment with a mandibular advancement splint: a 2-year follow-up. Eur J Orthod. 2000; 22:53-60.

44. Almeida FR, Lowe AA, Sung JO, Tsuiki S, Otsuka R. Longterm sequelae of oral appliance therapy in obstructive sleep apnea patients: Part 1. Cephalometric analysis. Am J Orthod Dentofacial Orthop. 2006; 129:195-204.

45. Marklund M, Franklin KA, Persson M. Orthodontic sideeffects of mandibular advancement devices during treatment of snoring and sleep apnoea. Eur J Orthod. 2001; 23:135-144. 